\title{
Gender and chronic kidney disease in ankylosing spondylitis: a single-center retrospectively study
}

Wenling Ye ${ }^{1 *} \mathbb{D}$, Jing Zhuang ${ }^{2}$, Yang Yu ${ }^{1}$, Hang Li ${ }^{1}$ Xiaomei Leng ${ }^{3}$, Jun Qian ${ }^{4}$, Yan Qin ${ }^{1}$, Limeng Chen ${ }^{1}$ and Xue-mei Li ${ }^{1}$

\begin{abstract}
Background: Ankylosing spondylitis (AS) is a well-known male-predominant inflammatory disease. This study aimed to assess the gender disparity in chronic kidney disease (CKD) in AS patients in China.

Methods: AS patients were retrospectively studied at Peking Union Medical College hospital between January 2002 and June 2018.

Results: Among 616 patients with AS, 154 (25.0\%) patients had CKD (age, $41.8 \pm 14.2$ years; male:female, 3.2:1). Overall, 80 (13.0\%) patients had only microscopic hematuria, 62 (10.1\%) had proteinuria with or without hematuria, and 33 (5.4\%) exhibited a reduced estimated glomerular filtration rate (eGFR, $\leq 60 \mathrm{~mL} / \mathrm{min} / 1.73 \mathrm{~m}^{2}$ ). Male CKD patients had more frequent proteinuria $(p<0.01)$, less microscopic hematuria only $(p<0.01)$, and lower eGFR $(p=0.04)$ compared with females. CKD was independently associated with hyperuricemia and total cholesterol in females, and with hyperuricemia, hypertension, and serum albumin in males. After follow-up for 1-7 years, five patients required renal replacement therapy including two patients who were already at stage 5 CKD when enrolled and three patients whose creatinine doubled. One patient died in the male group. No patients in the female group showed progression of renal dysfunction.

Conclusions: CKD is a common comorbidity in patients with AS. Male patients are more likely to develop severe manifestations compared with female patients. Hyperuricemia was a strong independent risk factor for CKD in both genders, while hypertension and low serum albumin were risk factors for CKD only in males.
\end{abstract}

Keywords: Ankylosing spondylitis, Chronic kidney disease, Gender difference, Hyperuricemia, Hypertension

\section{Background}

Ankylosing spondylitis (AS) is a chronic progressive inflammatory disease that primarily involves the spine and sacroiliac joints. The prevalence of AS was estimated to be $0.24 \%$ in Europe, $0.32 \%$ in North America, and $0.17 \%$ in Asia [1]. AS has been widely accepted as a malepredominant disease with a male-to-female ratio that was estimated to be as high as $9-10$ in early studies [2, 3], and it ranges between 3.2:1 and 6.1:1 in most studies [4-8]. Studies have shown that there might be gender-attributable

\footnotetext{
* Correspondence: wenlyepumch@163.com

'Department of Nephrology, Peking Union Medical College Hospital, Chinese Academy of Medical Sciences \& Peking Union Medical College, Shuifuyuan 1, Wangfujing, Beijing 100730, China

Full list of author information is available at the end of the article
}

differences in patients with AS regarding disease characteristics, clinical outcomes, and radiographic damage, as well as in the response to treatment. Male patients are more likely to have a younger age of disease onset, more typical features, more severe and faster progression of radiographic structural damage, more common anterior uveitis, and a higher frequency of human leukocyte antigen B27 (HLAB27) compared with female patients [5, 7, 9-12]. Females with AS show more active disease, less peripheral arthritis and functional disability as well as less psoriasis and a relatively worse treatment response with respect to both disease activity and functional outcome $[6,7,9,11,13,14]$.

AS can involve multiple systems and cause severe damage, especially the kidney, which is one of the systems commonly affected by AS. Several case series

(c) The Author(s). 2019 Open Access This article is distributed under the terms of the Creative Commons Attribution 4.0 International License (http://creativecommons.org/licenses/by/4.0/), which permits unrestricted use, distribution, and 
indicated the prevalence rate of renal involvement in AS is approximately 8.0 to $21.7 \%[4,8,15]$. Renal involvement in patients with AS has been attributed to multiple factors, including the use of nephrotoxic medication, the presence of comorbidities such as hypertension, and complications $[4,16,17]$. We speculate that there may be a gender difference regarding involvement of the kidney in AS. However, few studies have investigated the gender disparity of CKD manifestation and prognosis or have focused on the risk factors for CKD in AS. Therefore, this study was designed to evaluate the possible contribution of gender to differences in clinal features, disease progression, and risk factors of CKD in AS.

\section{Methods}

\section{Patient selection}

This retrospective cohort study was conducted using patient-level data at the Peking Union Medical College Hospital between January 2012 and May 2018. All diagnoses of AS were confirmed by a rheumatological specialist. Inclusion criteria included: (1) patients who fulfilled the New York diagnostic criteria for AS established by the American College of Rheumatology (ACR) in 1984 [18]; (2) no signs of systemic lupus erythematosus, anti-neutrophil cytoplasmic antibody (ANCA)-associated vasculitis, acute infectious diseases, or malignant diseases; and (3) patients who were over 18 years old.

Baseline information was obtained from the patient's first hospitalization. Detailed information regarding peripheral arthritis, extra-articular manifestations, presence of comorbidities, medications used for AS, physical examination and laboratory test results were recorded. Extra-articular manifestations and comorbidities included inflammatory bowel disease (IBD), uveitis, hypertension, diabetes, and kidney stones. History or current medications mainly included non-steroidal anti-inflammatory drugs (NSAIDs), disease-modifying anti-rheumatic drugs (DMARDs), or anti-tumor necrosis factor drugs (antiTNFs). Laboratory tests included hemoglobin, routine urinalysis and 24-h urine protein, serum creatinine, uric acid, albumin, alanine transaminase (ALT) and lipid profile. Serum creatinine was tested by enzymatic methods. For human leukocyte antigen B27 (HLA-B27), only the tests performed at our hospital were analyzed. Acutephase reactants included erythrocyte sedimentation rate (ESR) and C-reactive protein (CRP) levels. The estimated glomerular filtration rate (eGFR) was calculated based on the equation developed by the CKD-Epidemiology collaboration group (CKD-EPI) [19].

Patients were followed-up until June 2019 or until the primary outcome was reached. Every year follow-up information including serum creatinine, albumin, proteinuria, and whether renal replacement was initiated, was recorded since the first hospitalization. The composite primary outcome consisted of all-cause death, doubling of baseline serum creatinine, and/or dialysis initiation.

\section{Definitions}

CKD was defined based on the Kidney Disease Outcomes Quality Initiative (K/DOQI) guidelines when patients had one of following abnormalities for 3 months or more [20]: (1) proteinuria; (2) microscopic hematuria; or (3) estimated glomerular filtration rate (eGFR) $<60 \mathrm{~mL} / \mathrm{min} /$ $1.73 \mathrm{~m}^{2}$. Proteinuria was considered to be either of at least grade $1+$ by semiquantitative tests for urine albumin or proteinuria greater than $150 \mathrm{mg} / 24 \mathrm{~h}$. Hematuria was defined as the presence of more than three red blood cells at a high magnification of the urinary sediment, or more than 80 red cells per microliter. Patients with hematuria underwent urinary sediment analysis to screen for dysmorphic erythrocytes. Nephrotic syndrome was defined as proteinuria greater than $3.5 \mathrm{~g} / 24 \mathrm{~h}$ and a serum albumin level $<30 \mathrm{~g} / \mathrm{L}$. CKD was classified into five stages based on the K/DIGO Clinical Practice classification [20]: stage 1, eGFR $90-120 \mathrm{~mL} / \mathrm{min} / 1.73 \mathrm{~m}^{2}$; stage 2, eGFR $60-$ $89 \mathrm{~mL} / \mathrm{min} / 1.73 \mathrm{~m}^{2}$; stage 3 , eGFR $30-59 \mathrm{~mL} / \mathrm{min} /$ $1.73 \mathrm{~m}^{2}$; stage 4 , eGFR $15-29 \mathrm{~mL} / \mathrm{min} / 1.73 \mathrm{~m}^{2}$; and stage 5 , eGFR $<15 \mathrm{~mL} / \mathrm{min} / 1.73 \mathrm{~m}^{2}$. Renal dysfunction was defined as eGFR $<60 \mathrm{~mL} / \mathrm{min} .1 .73 \mathrm{~m}^{2}$. End-stage renal disease (ESRD) was defined as an eGFR $<15 \mathrm{~mL} /$ $\min / 1.73 \mathrm{~m}^{2}$ or the need to start dialysis. Hypertension was defined as receiving antihypertensive medications, or systolic blood pressure $\geq 140 \mathrm{mmHg}$, or diastolic blood pressure $\geq 90 \mathrm{mmHg}$. Hyperuricemia was defined as serum uric acid level $>416 \mu \mathrm{mol} / \mathrm{L}$ in males, $>357 \mu \mathrm{mol} / \mathrm{L}$ in females, or a history of hyperuricemia [21].

\section{Statistical analysis}

Statistical analysis was performed using SPSS version 21.0 (IBM, Armonk, NY, USA). Continuous variables with a normal distribution were expressed as the mean \pm standard deviation (SD) and analyzed using the independent-sample $t$-test. Data with a non-normal distribution were expressed as the median and interquartile range and compared using the non-parametric MannWhitney $U$-test. The chi-square test was used to assess categorical variables. Multivariate logistic regression models with CKD or non-CKD as dependent variables were constructed to assess risk factors associated with CKD in two genders separately. Age, duration of AS, HLA-B27 positivity, the presence of hyperuricemia, hypertension, diabetes or kidney stones, ESR, CRP, serum albumin, triglyceride and total cholesterol were introduced into the multiple logistic regression model and analyzed by a stepwise process. Kaplan-Meier curves were constructed for primary outcome over time. The few missing data were supplemented by mean values for normal distribution variables or by the median 
for non-normal distribution variables. HLA-B27 was tested in approximately two thirds of patients in our hospital. The missing values of HLA-B27 were randomly treated with gender-specific ratios in this study. A twosided value of $p<0.05$ was considered statistically significant for all analyses.

\section{Results}

\section{Characteristics of patients with ankylosing spondylitis}

The clinical characteristics of patients with AS are shown in Table 1. Overall, 616 patients were enrolled in this study. There were 468 male patients and 148 female patients with a male-to-female ratio of $3.2: 1$. The mean age of the patients was $41.8 \pm 14.2$ years, and the mean duration since AS diagnosis was $12.6 \pm 9.8$ years.

Table 1 Demographic and clinical features of patients with ankylosing spondylitis

\begin{tabular}{|c|c|}
\hline Variable & All patients $(n=616)$ \\
\hline Male, n (\%) & $468(76.0)$ \\
\hline Age, years & $41.8 \pm 14.2$ \\
\hline Duration of AS, years & $10.0(5.0,19.0)$ \\
\hline Peripheral arthritis, n (\%) & $300(48.7)$ \\
\hline IBD, n (\%) & $23(3.7)$ \\
\hline Uveitis, n (\%) & $68(11.0)$ \\
\hline Hyperuricemia, n (\%) & $119(19.3)$ \\
\hline Diabetes mellitus, n (\%) & $53(8.6)$ \\
\hline Hypertension, n (\%) & $138(22.4)$ \\
\hline Kidney stone, n (\%) & $24(3.9)$ \\
\hline \multicolumn{2}{|l|}{ Medication for AS } \\
\hline NSAIDs, n (\%) & $323(52.4)$ \\
\hline DMARDs, n (\%) & $270(43.8)$ \\
\hline Anti-TNFs, n (\%) & $72(11.7)$ \\
\hline $\mathrm{BMl}, \mathrm{kg} / \mathrm{m}^{2}$ & $23.5 \pm 4.4$ \\
\hline Systolic BP, mmHg & $125.2 \pm 18.2$ \\
\hline Diastolic BP, mmHg & $77.2 \pm 11.9$ \\
\hline Albumin, $\mathrm{g} / \mathrm{L}$ & $40.0 \pm 5.7$ \\
\hline Total cholesterol, mmol/L & $4.3 \pm 1.3$ \\
\hline Triglyceride, mmol/L & $1.3(0.8,1.6)$ \\
\hline Uric acid, $\mu \mathrm{mol} / \mathrm{L}$ & $336.1 \pm 111.3$ \\
\hline $\mathrm{ESR}, \mathrm{mm} / \mathrm{h}$ & $19.0(12.0,34.0)$ \\
\hline $\mathrm{CRP}, \mathrm{mg} / \mathrm{dL}$ & $10.2(3.1,28.1)$ \\
\hline Serum creatinine, $\mu \mathrm{mol} / \mathrm{L}$ & $67.0(57.0,77.0)$ \\
\hline eGFR, $\mathrm{mL} / \mathrm{min} / 1.73 \mathrm{~m}^{2}$ & $106.8 \pm 22.5$ \\
\hline HLA-B27 positive, n (\%) & $539(87.5)$ \\
\hline
\end{tabular}

Abbreviations: AS ankylosing spondylitis, IBD inflammatory bowel disease, NSAIDs non-steroidal anti-inflammatory drugs, DMARDs disease-modifying antirheumatic drugs, $T N F$ tumor necrosis factor, $B M I$ body mass index, $B P$ blood pressure, $A L T$ alanine transaminase, ESR erythrocyte sedimentation rate, CRP Creactive protein, eGFR estimated glomerular filtration rate, $H L A-B 27$ human leukocyte antigen B27
Positivity for HLA-B27 was observed in $87.7 \%$ of the patients. The prevalence of hyperuricemia and hypertension was $22.4 \%$ (138 patients) and $19.3 \%$ (119 patients), respectively. Among them, six (1.0\%) patients had a history of gout attacks.

\section{Gender comparison of chronic kidney disease in ankylosing spondylitis}

There were 154 (25.0\%) AS patients with CKD. Among them, 59 (9.6\%) patients presented with hematuria only and $80(13.0 \%)$ patients had proteinuria with or without hematuria (Table 2). Episodic gross hematuria occurred in five $(0.8 \%)$ patients and nephrotic syndrome in 11 (1.8\%) patients. Renal dysfunction was observed in 33 (5.4\%) patients.

Compared with female CKD patients, male CKD patients had less frequent hematuria, more common proteinuria, and lower eGFR (Tables 2 and 3). The prevalence of renal dysfunction was 6.2 and $2.7 \%$, respectively, in males and females, and two patients in the male group were already in ESRD. Additionally, male CKD patients were younger at AS onset and had a higher body mass index (BMI), more frequent hypertension, and a higher level of uric acid compared with females (Table 3). HLA positivity was more frequent in males compared with females. AS duration, IgA levels, ESR, and CRP were not significantly different between male and female patients.

\section{The risk factors associated with chronic kidney disease in both genders}

Compared with non-CKD patients with AS, male CKD patients had more common hyperuricemia and hypertension, higher total cholesterol and triglyceride levels, lower albumin levels, higher ESR level, and more common renal dysfunction (Table 3). In female patients, only the prevalence of hyperuricemia, total cholesterol level, and eGFR were significantly different between CKD and non-CKD patients.

Age, duration of AS, HLA-B27 positivity, the presence of hyperuricemia, hypertension, diabetes or kidney stones, ESR, CRP, serum albumin, triglyceride and total cholesterol, which might be associated with CKD development, were introduced into the multiple logistic regression model. They were analyzed by a forward stepwise process in female and male patients separately. Logistic regression showed that hyperuricemia, hypertension, high total cholesterol level, and low albumin were independent risk factors for CKD development in male patients. In female patients, only hyperuricemia and total cholesterol hypertension were independent factors that were associated with CKD (Table 4). 
Table 2 The prevalence and clinical manifestations of chronic kidney disease in ankylosing spondylitis

\begin{tabular}{|c|c|c|c|c|}
\hline & $\begin{array}{l}\text { All patients } \\
(n=616)\end{array}$ & $\begin{array}{l}\text { Males } \\
(n=468)\end{array}$ & $\begin{array}{l}\text { Females } \\
(n=148)\end{array}$ & $p$ value \\
\hline CKD, n (\%) & $154(25.0)$ & $119(25.4)$ & $35(23.6)$ & 0.74 \\
\hline \multicolumn{5}{|l|}{ Clinical manifestations } \\
\hline Hematuria only, n (\%) & $59(9.6)$ & $35(7.5)$ & $24(16.2)$ & $<0.01$ \\
\hline Proteinuria, n (\%) & $80(13.0)$ & $72(15.4)$ & $8(5.4)$ & $<0.01$ \\
\hline eGFR $\leq 60 \mathrm{~mL} / \mathrm{min} / 1.73 \mathrm{~m}^{2}, \mathrm{n}(\%)$ & $33(5.4)$ & $29(6.2)$ & $4(2.7)$ & 0.15 \\
\hline \multicolumn{5}{|l|}{ CKD stages $^{\mathrm{a}}$} \\
\hline 1 & $100(64.9 \%)$ & $72(60.5 \%)$ & $28(80.0 \%)$ & \\
\hline 2 & $21(13.6 \%)$ & $18(15.1 \%)$ & $3(8.6 \%)$ & \\
\hline 3 & $27(17.5 \%)$ & $24(20.2 \%)$ & $3(8.6 \%)$ & \\
\hline 4 & $4(2.6 \%)$ & $3(2.5 \%)$ & $1(2.9 \%)$ & \\
\hline 5 & $2(1.3 \%)$ & $2(1.7 \%)$ & $0(0.0 \%)$ & \\
\hline
\end{tabular}

Abbreviations: CKD chronic kidney disease, eGFR estimated glomerular filtration rate

${ }^{\text {a }}$ Patients with chronic kidney disease were used as the denominator to calculate the percentage

Outcomes of chronic kidney disease in both genders

Excluding 15 patients who were lost to follow-up, the mean follow-up duration was $2.8 \pm 1.6$ years (range, $1-7$ years). A Kaplan-Meier curve by gender category showed that gender was not significantly associated with the primary outcome (log rank test, $p=0.12$ ) (Fig. 1). All patients with renal function decline were in the male group. Overall, seven patients in the male group reached the primary outcome after 3.0 years of follow-up, excluding two patients who were already on hemodialysis at the time of enrollment. Among the seven patients, three patients entered ESRD and received renal replacement therapy after 1.5-3 years, three patients showed a doubling of creatinine levels, and one patient whose renal

Table 3 Comparison of clinical characteristics of CKD and non-CKD patients between genders

\begin{tabular}{|c|c|c|c|c|c|c|c|}
\hline \multirow[t]{2}{*}{ Variable } & \multicolumn{3}{|l|}{ Females } & \multicolumn{3}{|l|}{ Males } & \multirow{2}{*}{$\begin{array}{l}p \text { value of female } \\
\text { vs male CKD }\end{array}$} \\
\hline & non-CKD $(n=113)$ & CKD $(n=35)$ & $p$ value & non-CKD $(n=349)$ & CKD $(n=119)$ & $p$ value & \\
\hline Age, years & $43.0 \pm 13.3$ & $46.5 \pm 13.7$ & 0.18 & $41.1 \pm 13.9$ & $41.3 \pm 15.7$ & 0.89 & 0.08 \\
\hline Age at AS onset, years & $31.7 \pm 14.1$ & $35.8 \pm 11.4$ & 0.13 & $27.7 \pm 13.3$ & $28.0 \pm 12.5$ & 0.86 & $<0.01$ \\
\hline Duration of AS, years & $10.0(5.0,16.0)$ & $6.0(3.0,18.0)$ & 0.64 & $12.0(6.0,20.0)$ & $10.0(5,0,19.0)$ & 0.20 & 0.39 \\
\hline Peripheral arthritis, n (\%) & $47(41.6)$ & $14(40.0)$ & 1.00 & $181(51.9)$ & $58(48.7)$ & 0.60 & 0.44 \\
\hline Hyperuricemia, n (\%) & $5(4.4)$ & $7(20.0)$ & 0.01 & $63(18.1)$ & $44(37.0)$ & $<0.01$ & 0.07 \\
\hline Hypertension, n (\%) & $19(16.8)$ & $6(17.1)$ & 1.00 & $68(19.5)$ & $45(37.8)$ & $<0.01$ & 0.03 \\
\hline Diabetes mellitus, n (\%) & $8(7.1)$ & $2(5.7)$ & 1.00 & $29(8.3)$ & $14(11.8)$ & 0.27 & 0.53 \\
\hline Kidney stone, n (\%) & $0(0.0)$ & $0(0.0)$ & - & $14(4.0)$ & $10(8.4)$ & 0.09 & 0.12 \\
\hline HLA-B27 positivity, n (\%) & $88(77.9)$ & $27(77.1)$ & 0.93 & $310(88.8)$ & $114(95.8)$ & 0.02 & $<0.01$ \\
\hline \multicolumn{8}{|l|}{ Medication use } \\
\hline NSAIDs, n (\%) & $61(54.0)$ & $15(42.9)$ & 0.33 & $190(54.4)$ & $57(47.9)$ & 0.34 & 0.70 \\
\hline DMARDs, n (\%) & $50(44.2)$ & $18(51.4)$ & 0.56 & $154(44.1)$ & $48(40.3)$ & 0.52 & 0.25 \\
\hline Anti-TNF-a, n (\%) & $10(8.8)$ & $5(14.3)$ & 0.35 & $45(12.9)$ & $12(10.1)$ & 0.52 & 0.54 \\
\hline $\mathrm{eGFR}, \mathrm{mL} / \mathrm{min} / 1.73 \mathrm{~m}^{2}$ & $111.4 \pm 15.2$ & $100.8 \pm 25.7$ & 0.03 & $111.7 \pm 16.0$ & $89.8 \pm 32.8$ & $<0.01$ & 0.04 \\
\hline Serum creatinine, $\mu \mathrm{mol} / \mathrm{L}$ & $53.0(47.0,59.0)$ & $56.0(46.0,67.0)$ & 0.12 & $69.0(62.0,75.0)$ & $80(70.0,123.0)$ & $<0.01$ & $<0.01$ \\
\hline Albumin, $g / L$ & $41.1 \pm 4.8$ & $39.2 \pm 6.6$ & 0.11 & $40.7 \pm 5.0$ & $37.3 \pm 7.1$ & $<0.01$ & 0.16 \\
\hline Total cholesterol, mmol/L & $4.3 \pm 1.1$ & $4.8 \pm 1.1$ & 0.04 & $4.1 \pm 1.0$ & $4.6 \pm 2.0$ & 0.04 & 0.55 \\
\hline Triglyceride, $\mathrm{mmol} / \mathrm{L}$ & $1.3(0.8,1.4)$ & $1.4(0.8,1.4)$ & 0.17 & $1.2(0.8,1.4)$ & $1.5(0.8,1.8)$ & $<0.01$ & 0.37 \\
\hline $\mathrm{CRP}, \mathrm{mg} / \mathrm{dL}$ & $6.1(1.9,19.9)$ & $8.6(1.8,38.9)$ & 0.29 & $12.5(4.0,32.0)$ & $12.6(3.2,26.8)$ & 0.36 & 0.67 \\
\hline $\mathrm{ESR}, \mathrm{mm} / \mathrm{h}$ & $23.0(18.0,32.0)$ & $28.0(19.0,37.0)$ & 0.10 & $17.0(11.0,31.0)$ & $23.0(14.0,44.0)$ & $<0.01$ & 0.31 \\
\hline
\end{tabular}

Abbreviations: $A S$ ankylosing spondylitis, HLA-B27 human leukocyte antigen B27, NSAIDs non-steroidal anti-inflammatory drugs, DMARDs disease-modifying antirheumatic drugs, TNF tumor necrosis factor, eGFR estimated glomerular filtration rate, CRP c-reactive protein, ESR erythrocyte sedimentation rate 
Table 4 Factors associated with CKD analyzed by logistic regression based on gender

\begin{tabular}{lll}
\hline Variable & Odds ratio $(95 \% \mathrm{Cl})$ & $p$ value \\
\hline Females & & \\
Hyperuricemia $(1=$ yes $)$ & $5.14(1.39,19.04)$ & 0.01 \\
$\quad$ Total cholesterol, $1 \mathrm{mmol} / \mathrm{L}$ & $2.17(1.32,3.58)$ & $<0.01$ \\
Males & & \\
Hyperuricemia (1 =yes) & $2.58(1.57,4.22)$ & $<0.01$ \\
Hypertension (1 =yes) & $2.40(1.48,3.90)$ & $<0.01$ \\
Albumin, $1 \mathrm{~g} / \mathrm{L}$ & $0.90(0.86,0.93)$ & $<0.01$
\end{tabular}

Abbreviations: $\mathrm{Cl}$ confidence interval, CKD or non-CKD as dependent factor and age, duration of AS, HLA-B27 positivity, the presence of hyperuricemia, hypertension, diabetes or kidney stones, erythrocyte sedimentation rate, Creactive protein, serum albumin, triglyceride, and total cholesterol as dependent factors

creatinine was doubled before death died of pulmonary infection. In the female group, no primary outcome was observed after an average follow-up of 2.9 years.

\section{Discussion}

AS, which is a form of spondyloarthritis, is a chronic, multisystemic inflammatory disease that primarily involves the spine and the sacroiliac joints. The most common extra-articular manifestations are uveitis, bowel disease, and heart, lung, and skin conditions. Renal involvement is also common in AS. In a population-based study from Canada, the occurrence of renal complications consisted of acute kidney injury, CKD, amyloidosis, and hypertensive renal disease, and they occurred in $3.4 \%$ of men and $2.1 \%$ of women with AS [22]. The present study showed a frequency of CKD in patients with AS of $25.0 \%$. Compared with a prevalence of CKD from 9.2 to $10.8 \%$ in the Chinese general population
[23, 24], this study showed that the prevalence of CKD is much higher in AS patients.

AS is considered a disease that occurs predominantly in males. In the present study, the male-to-female ratio was 3.2:1. Several studies have revealed that differences exist in clinical manifestation, age of disease onset, radiographic skeletal damage, medication response, and disease progression between males and females with AS [5-7, 9-14]. However, few published studies have investigated gender-attributable differences with respect to CKD in patients with AS. Understanding the genderassociated differences in disease progression and risk factors for CKD in AS are important to guide disease prevention strategies and further treatment in individuals with these coexisting conditions.

In the present study, clinical manifestations of CKD varied from microscopic hematuria and proteinuria to nephrotic syndrome, and from mild-renal dysfunction to ESRD. Proteinuria with or without hematuria was the most common presentation of renal involvement, affecting $13.0 \%$ of patients, while $9.6 \%$ patients presented with hematuria only and $5.4 \%$ patients developed renal dysfunction. Wu et al. reported that among the $926 \mathrm{AS}$ patients, $21.7 \%$ patients had renal involvement, including $14.3 \%$ with hematuria, $4.8 \%$ with proteinuria, $0.1 \%$ with reduced eGFR, and $2.6 \%$ with multiple renal involvement manifestations [8]. In a retrospective single-center study from South Korea, $8 \%$ of AS patients had abnormal urinalysis test results as follows: proteinuria (5.9\%), hematuria $(2.8 \%)$, or both $(0.7 \%)$ [4]. In our study, the prevalence of proteinuria and renal dysfunction were much higher compared with these two studies from Asia. However, compared with these two studies, patients enrolled in our study were older and had a longer

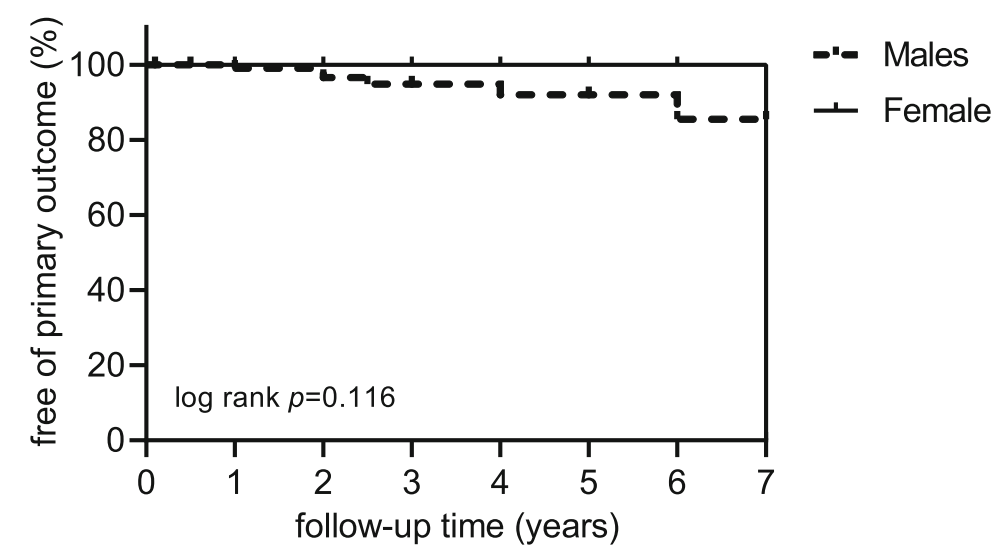

$\begin{array}{lrrrrrrr}\text { Male(n) } & 107 & 80 & 50 & 24 & 16 & 8 & 5 \\ \text { Female(n) } & 30 & 21 & 16 & 12 & 11 & 2 & 1\end{array}$

Fig. 1 Primary outcome over time in male and female CKD patients. Primary outcome consisted of doubling of serum creatinine, dialysis initiation or all cause death 
duration of AS $[4,8]$. These differences may explain the differences in CKD severity between the three studies. However, the differences in these results also indicate that the prevalence and severity of CKD may increase with the patient's age and the duration of their disease.

We found that clinical manifestations of CKD showed gender disparity. Male CKD patients had less frequent hematuria $(p<0.01)$, more frequent proteinuria $(p<$ $0.01)$, and a lower eGFR $(p=0.04)$. Although a KaplanMeier curve did not show a significant association between gender and CKD outcome, all patients with renal function decline were in the male group. However, in the female group, no primary outcome was observed after follow-up. These results suggested that renal involvement was worse in males compared with females. In previous studies $[5,7,10]$, male patients had a younger age of AS onset, a higher BMI, more frequent occurrence of hypertension, and a higher level of uric acid compared with female patients in this study. Additionally, HLA positivity was more frequent in males compared with females.

Few studies have investigated the risk factors of CKD in AS. In a study that enrolled 681 patients, uric acid and IgA levels were significantly higher in patients with proteinuria compared with those without proteinuria [4]. An international, cross-sectional study that enrolled 2098 patients showed that age, HLA-B27 positivity, and CRP were independently associated with renal impairment (eGFR $<60 \mathrm{~mL} / \mathrm{min} / 1.73 \mathrm{~m}^{2}$ ) in patients with spondyloarthritis [25]. In this study, we used CKD to evaluate renal involvement including hematuria, proteinuria, and chronic renal dysfunction based on the $\mathrm{K} /$ DOQI criteria. To assess the possible disparity of risk factors for CKD in AS, we divided patients into CKD and non-CKD groups based on two genders (male and female). Male CKD patients had more frequent hyperuricemia, hypertension and HLA-B27 positivity, higher total cholesterol and triglyceride levels, lower albumin levels, higher ESR and more common renal dysfunction compared with non-CKD patients. A multivariate logistic regression analysis showed that hyperuricemia, hypertension, and serum albumin level were independent risk factors for the development of CKD in males. However, hyperuricemia and total cholesterol were independent factors for CKD in female patients. No differences in HLA-B27 positivity and AS disease activity were found between CKD and nonCKD groups in the two genders.

The present study showed that hyperuricemia had the strongest association with CKD in AS patients of both genders, showing that hyperuricemia may play an important role in the CKD development in this population. Although only $1.0 \%$ of patients experienced a gout attack, the prevalence of hyperuricemia was $19.3 \%$ overall and $33.1 \%$ in CKD patients. A previous study showed that uric acid was a strong correlate of renal dysfunction in RA patients [26]. Studies in the general population and in patients with diabetes or CKD also confirmed the association of hyperuricemia with the development and progression of kidney disease [27-29]. In two communitybased cohorts involving 13,338 healthy participants who were followed for a mean of 8.5 years, every $1 \mathrm{mg} / \mathrm{dL}$ increase in baseline serum uric acid level was associated with a $7 \%$ increased risk for developing kidney disease (defined as an eGFR $<60 \mathrm{~mL} / \mathrm{min} / 1.73 \mathrm{~m}^{2}$ ) [28]. An investigation of 324 patients in the Coronary Artery Calcification in Type I Diabetes (CACTI) study showed that for every $1 \mathrm{mg} / \mathrm{dL}$ increase in uric acid at baseline, there was an $80 \%$ increased risk of developing micro- or macroalbuminuria [29]. Several underlying mechanisms have been proposed for these effects [30, 31]. Uric acid crystals can adhere to the surface of renal epithelial cells and induce tubulointerstitial inflammation [32]. Hyperuricemia had effects on glomerular hemodynamics by increasing renal vascular resistance [30]. Uric acid may directly affect endothelial smooth muscle cells in the vascular walls by blocking nitric oxide release, and inducing afferent renal arteriolopathy through effects on the renin-angiotensinaldosterone system [33-36]. A clinical study confirmed these findings, showing that hyperuricemia was significantly associated with a higher risk of renal arteriolar hyalinosis and higher-grade wall thickening in patients with CKD [37]. Additionally, hyperuricemia is also associated with a greater risk of kidney stones, which have been shown to increase the risk of CKD and reduced eGFR [38]. In our study, kidney stones occurred in $3.9 \%$ of AS patients, but no association was observed between urolithiasis and CKD, suggesting that urolithiasis is not a main risk factor in this population.

The increasing prevalence of hyperuricemia appears to have various causes, including increased longevity, obesity, alcohol consumption, and a high dietary intake of meat and seafood [39]. Hyperuricemia may also be related to risk factors associated with medications that are used for AS or coexisting comorbidities. Several medications have been associated with the development of hyperuricemia by impairing uric acid excretion [40, 41]. DMARDs are widely used for second-line therapy in AS. Sulfasalazine is the most extensively studied DMARDs and more than $40 \%$ of patients received sulphasalazine treatment in the present study. Although sulphasalazine has not been shown to be associated with hyperuricemia, the pharmacokinetics of sulphasalazine were reviewed to identify any association with hyperuricemia [42]. Additionally, diuretics, low-dose aspirin, angiotensin converting enzyme inhibitors, and non-losartan angiotensin II receptor blockers were prescribed for some patients, including patients with hypertension, congestive heart failure, coronary heart disease, and stroke. Those medications may affect 
hyperuricemia to some degree. Additionally, hyperuricemia is the result of dysfunctional urate homeostasis. Approximately two-thirds of the uric acid produced in humans is excreted by the kidneys [43]. Renal impairment can further interfere with renal excretion of uric acid and aggravate hyperuricemia.

This study showed that hypertension was a common comorbidity in the AS population, and the overall prevalence of hypertension was $22.4 \%$ in AS patients. A previous study also showed that the prevalence of hypertension in patients with AS was more frequent compared with matched cohorts [44]. In our study, the prevalence of hypertension was significantly higher in male CKD patients compared with female CKD patients $(37.8 \%$ vs $17.1 \%, p=0.025)$ and multiple regression analysis showed that hypertension is a risk factor for CKD only for male patients. The potential mechanism involved is unclear although it might be related to the role of sex hormones. Observational studies suggest gender differences in the prevalence or outcome of AS, hypertension, and CKD $[6,45,46]$. Male hormones exert a deleterious effect in terms of activating the renin-angiotensin system (RAS), stimulating endothelin synthesis, and increasing oxidative stress, which are closely associated with hypertension and renal injury. Testosterone increased efferent arteriolar resistance by activating the RAS and increased angiotensin type 1 receptor expression in mesangial cells $[45,47]$. Estrogen inhibits endothelin synthesis and restrains its vasoconstrictor effects, whereas testosterone has the opposite effect. Testosterone also increased oxidative stress by increasing the generation of reactive oxygen species and by inhibiting antioxidant enzymes to increase blood pressure and aggravate renal injury [45].

It is well-known that the occurrence of hypertension increases the risk of all renal complications. Several potential mechanisms that were studied in other conditions have been explored to examine the association between uric acid and hypertension. Hyperuricemia promotes the development of hypertension and induces a renal arteriolopathy by causing vascular smooth muscle cell proliferation and activating the RAS [35]. Clinical data also support a potential link between uric acid and hypertension. A recent study assessing the long-term efficacy of lowering uric acid with febuxostat on hypertension and renal function showed that lowering uric acid levels was an effective treatment for hypertension and CKD progression [48]. The causal relationship between hyperuricemia and hypertension in the development of CKD in AS requires further investigation.

HLA-B27 is the main genetic component of AS susceptibility. Its prevalence is lower among women with AS compared with men in several studies $[5,7,13]$. An international study investigating comorbidities in SpA showed that HLA-B27 positivity was significantly associated with renal impairment (eGFR $<60 \mathrm{~mL} / \mathrm{min}$ / $1.73 \mathrm{~m}^{2}$ ) [25]. In our study, HLA-B27 positivity was observed in $87.5 \%$ of patients and it was also more frequent in male CKD patients compared with male non-CKD patients $(95.8 \%$ vs $77.1 \%, p<0.01)$. However, HLA-B27 positivity did not independently correlate with the presence of CKD in both genders. The differing results between the two studies may be related to the patients' ethnic backgrounds.

\section{Conclusions}

Our findings suggest that there were some gender differences in the clinical manifestations and risk factors of CKD in patients with AS. The manifestations of renal involvement seem to be more severe in males compared with females, although the prevalence of CKD was similar. The presence of hyperuricemia was a strong predictor of renal involvement for both genders of AS patients, while hypertension and low serum albumin are specific predictors for CKD only in male patients. This study suggests that AS patients with elevated uric acid and hypertension, especially in males, may require screening for CKD and appropriate management.

There are some important limitations in this study. First, the prevalence of CKD may be overestimated compared with the general AS patient population. More severely affected patients who needed hospitalization were enrolled in this study, and therefore, this might have introduced selection bias. Second, the duration of followup (mean, 2.8 years) was not long enough to reach the primary outcome for most of the patients. A longer follow-up duration is warranted to further investigate the impact of gender on disease progression and renal prognosis in this population. Despite the limitations described above, this is the first study to focus on gender disparity in Chinese patients with AS and the findings presented here could help to elucidate the potential influence of gender on clinical features, disease severity, and risk factors for CKD in this population.

\section{Abbreviations \\ ALT: Alanine transaminase; anti-TNF: Anti-tumor necrosis factor; AS: Ankylosing spondylitis; CKD: Chronic kidney disease; CRP: C-reactive protein; DMARDs: Disease-modifying anti-rheumatic drugs; eGFR: Estimated glomerular filtration rate; ESR: Erythrocyte sedimentation rate; ESRD: End- stage renal disease; HLA-B27: Human leukocyte antigen B27; IBD: Inflammatory bowel disease; Ig: Immunoglobulin; K/DOQI: The Kidney Disease Outcomes Quality Initiative; NSAIDs: Non-steroidal anti-inflammatory drugs}

\section{Acknowledgments}

We thank Jodi Smith, PhD, from Liwen Bianji, Edanz Editing China (www. liwenbianji.cn/ac), for editing the English text of a draft of this manuscript.

\section{Authors' contributions}

WY was the major contributor in the study design, performed data analysis, and drafting the manuscript. JZ mainly participated in data acquisition and coordination of the study. YY, HL, YQ and LC provided some important ideas for this study and participated in data analysis. XL1 and JQ collected 
important background information and assisted for interpretation of data. XL2 revised the manuscript and provided intellectual content of critical importance to the study. All authors read and approved the final manuscript.

\section{Funding}

This work was funded by the Chinese National Key Technology R and D Program, Ministry of Science and Technology (No. 2017YFC0907603). The funding bodies didn't take part either in the design of the study or in collection, analysis, and interpretation of data or in writing the manuscript.

\section{Availability of data and materials}

The datasets used and analyzed during the current study are available from the corresponding author on reasonable request.

\section{Ethics approval and consent to participate}

All procedures performed in this study were conducted in accordance with the ethical standards of the Ethics Committee at Peking Union Medical College Hospital (Approval number, SK-815) and with the 1964 Declaration of Helsinki and its later amendments or comparable ethical standards. For this type of study, the need of consent was waived by the Ethics Committee at Peking Union Medical College Hospital.

\section{Consent for publication}

Not applicable.

\section{Competing interests}

The authors declare that they have no competing interests.

\section{Author details}

'Department of Nephrology, Peking Union Medical College Hospital, Chinese Academy of Medical Sciences \& Peking Union Medical College, Shuifuyuan 1, Wangfujing, Beijing 100730, China. ${ }^{2}$ Department of Nephrology, People's Hospital of Xinjiang, Uygur Autonomous Region 830001, China. ${ }^{3}$ Department of Rheumatology and Clinical Immunology, Peking Union Medical College Hospital, Chinese Academy of Medical Sciences \& Peking Union Medical College, Beijing 100730, China. ${ }^{4}$ Department of Orthopedics, Peking Union Medical College Hospital, Chinese Academy of Medical Sciences \& Peking Union Medical College, Beijing 100730, China.

Received: 15 September 2019 Accepted: 3 December 2019

\section{Published online: 09 December 2019}

\section{References}

1. Dean LE, Jones GT, MacDonald AG, Downham C, Sturrock RD, Macfarlane GJ. Global prevalence of ankylosing spondylitis. Rheumatology (Oxford, England). 2014;53(4):650-7.

2. Polley HF, Slocumb CH. Rheumatoid spondylitis; a study of 1,035 cases. Ann Rheum Dis. 1947;6(2):95-8.

3. West HF. Aetiology of Ankylosing spondylitis. Ann Rheum Dis. 1949;8(2): $143-8$.

4. Lee SH, Lee EJ, Chung SW, Song R, Moon JY, Lee SH, Lim SJ, Lee YA, Hong SJ, Yang HI. Renal involvement in ankylosing spondylitis: prevalence, pathology, response to TNF-a blocker. Rheumatol Int. 2013;33(7):1689-92.

5. Jung YO, Kim I, Kim S, Suh CH, Park HJ, Park W, Kwon SR, Jeong JC, Lee YJ, Ryu HJ, et al. Clinical and radiographic features of adult-onset ankylosing spondylitis in Korean patients: comparisons between males and females. J Korean Med Sci. 2010;25(4):532-5.

6. Landi M, Maldonado-Ficco H, Perez-Alamino R, Maldonado-Cocco JA, Citera G, Arturi P, Sampaio-Barros PD, Flores Alvarado DE, Burgos-Vargas R, Santos $E$, et al. Gender differences among patients with primary ankylosing spondylitis and spondylitis associated with psoriasis and inflammatory bowel disease in an iberoamerican spondyloarthritis cohort. Medicine. 2016;95(51):e5652.

7. de Carvalho HM, Bortoluzzo AB, Goncalves $C R$, da Silva JA, Ximenes AC, Bertolo MB, Ribeiro SL, Keiserman M, Menin R, Skare TL, et al. Gender characterization in a large series of Brazilian patients with spondyloarthritis. Clin Rheumatol. 2012;31(4):687-95.

8. Wu Y, Zhang G, Wang N, Xue Q. Risk factors of renal involvement based on different manifestations in patients with Ankylosing spondylitis. Kidney Blood Pressure Res. 2018;43(2):367-77.
9. Lee W, Reveille JD, Davis JC Jr, Learch TJ, Ward MM, Weisman MH. Are there gender differences in severity of ankylosing spondylitis? Results from the PSOAS cohort. Ann Rheum Dis. 2007;66(5):633-8.

10. Smith WM. Gender and spondyloarthropathy-associated uveitis. J Ophthalmol. 2013;2013:928264.

11. Exarchou S, Lindstrom U, Askling J, Eriksson JK, Forsblad-d'Elia H, Neovius M, Turesson C, Kristensen LE, Jacobsson LT. The prevalence of clinically diagnosed ankylosing spondylitis and its clinical manifestations: a nationwide register study. Arthritis Res Ther. 2015;17:118.

12. Roussou E, Sultana S. Spondyloarthritis in women: differences in disease onset, clinical presentation, and Bath Ankylosing spondylitis disease activity and functional indices (BASDAI and BASFI) between men and women with spondyloarthritides. Clin Rheumatol. 2011;30(1):121-7.

13. van der Horst-Bruinsma IE, Zack DJ, Szumski A, Koenig AS. Female patients with ankylosing spondylitis: analysis of the impact of gender across treatment studies. Ann Rheum Dis. 2013;72(7):1221-4.

14. Murray C, Fearon C, Dockery M, Moran D, Heffernan E, Fitzgerald O, Veale $D J$, Harty L. Ankylosing spondylitis response to TNF inhibition is gender specific: a 6-year cohort study. Ir Med J. 2018;111(9):820.

15. Ben Taarit C, Ajlani H, Ben Moussa F, Ben Abdallah T, Ben Maiz H. Khedher a: [renal involvement in ankylosing spondylitis: concerning 210 cases]. La Revue de Med Interne. 2005;26(12):966-9.

16. Barbouch S, Hajii M, Jaziri F, Aoudia R, Fellah E, Hedri H, Goucha R, Hamida FB, Taarit FB, Gorsane I, et al. Renal amyloidosis in ankylosing spondylitis: a monocentric study and review of literature. Saudi J Kidney Dis Transpl. 2018; 29(2):386-91.

17. Ozcakar L, Ekiz T, Yalcin S, Akinci A. IgA nephropathy in an ankylosing spondylitis patient during infliximab therapy: chicken, egg or mother and child Reunion? Acta Reumatologica Portuguesa. 2013;38(4):310.

18. van der Linden S, Valkenburg HA, Cats A. Evaluation of diagnostic criteria for ankylosing spondylitis. A proposal for modification of the New York criteria. Arthritis Rheum. 1984;27(4):361-8.

19. Levey AS, Stevens LA, Schmid CH, Zhang YL, Castro AF 3rd, Feldman HI, Kusek JW, Eggers P, Van Lente F, Greene T, et al. A new equation to estimate glomerular filtration rate. Ann Intern Med. 2009;150(9): $604-12$.

20. KJDOQI clinical practice guidelines for chronic kidney disease: evaluation, classification, and stratification. Am J Kidney Dis 2002, 39(2 Suppl 1):S1-266.

21. Sonoda H, Takase H, Dohi Y, Kimura G. Uric acid levels predict future development of chronic kidney disease. Am J Nephrol. 2011;33(4):352-7.

22. Levy AR, Szabo SM, Rao SR, Cifaldi M, Maksymowych WP. Estimating the occurrence of renal complications among persons with ankylosing spondylitis. Arthritis Care Res. 2014;66(3):440-5.

23. Zhang L, Wang F, Wang L, Wang W, Liu B, Liu J, Chen M, He Q, Liao Y, Yu X, et al. Prevalence of chronic kidney disease in China: a cross-sectional survey. Lancet. 2012;379(9818):815-22.

24. Shen Q, Jin W, Ji S, Chen X, Zhao X, Behera TR. The association between socioeconomic status and prevalence of chronic kidney disease: a crosssectional study among rural residents in eastern China. Medicine. 2019; 98(11):e14822.

25. Couderc M, Pereira B, Molto A, Tiple A, Soubrier M, Dougados M. The prevalence of renal impairment in patients with Spondyloarthritis: results from the international ASAS-COMOSPA study. J Rheumatol. 2018;45(6):795-801.

26. Daoussis D, Panoulas V, Toms T, John H, Antonopoulos I, Nightingale P, Douglas KM, Klocke R, Kitas GD. Uric acid is a strong independent predictor of renal dysfunction in patients with rheumatoid arthritis. Arthritis Res Ther. 2009;11(4):R116.

27. Srivastava A, Kaze AD, McMullan CJ, Isakova T, Waikar SS. Uric acid and the risks of kidney failure and death in individuals with CKD. Am J Kidney Dis. 2018;71(3):362-70.

28. Weiner DE, Tighiouart H, Elsayed EF, Griffith JL, Salem DN, Levey AS. Uric acid and incident kidney disease in the community. J Am Soc Nephrol. 2008;19(6):1204-11.

29. Jalal DI, Rivard CJ, Johnson RJ, Maahs DM, McFann K, Rewers M, SnellBergeon JK. Serum uric acid levels predict the development of albuminuria over 6 years in patients with type 1 diabetes: findings from the coronary artery calcification in type 1 diabetes study. Nephrol DialysisTranspl. 2010; 25(6):1865-9.

30. Sanchez-Lozada LG, Tapia E, Santamaria J, Avila-Casado C, Soto V, Nepomuceno T, Rodriguez-lturbe B, Johnson RJ, Herrera-Acosta J. Mild hyperuricemia induces vasoconstriction and maintains glomerular 
hypertension in normal and remnant kidney rats. Kidney Int. 2005;67(1): 237-47.

31. Isaka Y, Takabatake Y, Takahashi A, Saitoh T, Yoshimori T. Hyperuricemiainduced inflammasome and kidney diseases. Nephrology Dialysis Transpl. 2016;31(6):890-6.

32. Koka RM, Huang E, Lieske JC. Adhesion of uric acid crystals to the surface of renal epithelial cells. Am J Physiol Renal Physiol. 2000;278(6):F989-98.

33. Maruhashi T, Hisatome I, Kihara Y, Higashi Y. Hyperuricemia and endothelial function: from molecular background to clinical perspectives. Atherosclerosis. 2018;278:226-31.

34. De Becker B, Borghi C, Burnier M, van de Borne P. Uric acid and hypertension: a focused review and practical recommendations. J Hypertens. 2019;37(5):878-83.

35. Mazzali M, Kanellis J, Han L, Feng L, Xia YY, Chen Q, Kang DH, Gordon KL, Watanabe $\mathrm{S}$, Nakagawa T, et al. Hyperuricemia induces a primary renal arteriolopathy in rats by a blood pressure-independent mechanism. Am J Physiol Renal Physiol. 2002;282(6):F991-7.

36. Milanesi S, Verzola D, Cappadona F, Bonino B, Murugavel A, Pontremoli R, Garibotto G, Viazzi F. Uric acid and angiotensin II additively promote inflammation and oxidative stress in human proximal tubule cells by activation of toll-like receptor 4. J Cell Physiol. 2019;234(7):10868-76.

37. Kohagura K, Kochi M, Miyagi T, Kinjyo T, Maehara Y, Nagahama K, Sakima A, Iseki K, Ohya Y. An association between uric acid levels and renal arteriolopathy in chronic kidney disease: a biopsy-based study. Hypertension Res. 2013;36(1):43-9.

38. Li CC, Chien TM, Wu WJ, Huang CN, Chou YH. Uric acid stones increase the risk of chronic kidney disease. Urolithiasis. 2018;46(6):543-7.

39. Li R, Yu K, Li C. Dietary factors and risk of gout and hyperuricemia: a metaanalysis and systematic review. Asia Pac J Clin Nutr. 2018;27(6):1344-56.

40. Ben Salem C, Slim R, Fathallah N, Hmouda H. Drug-induced hyperuricaemia and gout. Rheumatology. 2017;56(5):679-88.

41. Lapi F, Azoulay L, Yin H, Nessim SJ, Suissa S. Concurrent use of diuretics, angiotensin converting enzyme inhibitors, and angiotensin receptor blockers with non-steroidal anti-inflammatory drugs and risk of acute kidney injury: nested case-control study. BMJ (Clinical research ed). 2013;346:e8525.

42. Ho HH, Yu KH, Chen JY, Lin JL, Wu YJ, Luo SF, Liou LB. Coexisting ankylosing spondylitis and gouty arthritis. Clin Rheumatol. 2007;26(10):1655-61.

43. Jalal DI. Hyperuricemia, the kidneys, and the spectrum of associated diseases: a narrative review. Curr Med Res Opin. 2016:32(11):1863-9.

44. Ahmed N, Prior JA, Chen Y, Hayward R, Mallen CD, Hider SL. Prevalence of cardiovascular-related comorbidity in ankylosing spondylitis, psoriatic arthritis and psoriasis in primary care: a matched retrospective cohort study. Clin Rheumatol. 2016;35(12):3069-73.

45. Neugarten J, Golestaneh L. Influence of sex on the progression of chronic kidney disease. Mayo Clin Proc. 2019;94(7):1339-56.

46. Song JJ, Ma Z, Wang J, Chen LX, Zhong JC: Gender Differences in Hypertension. J Cardiovasc Transl Res 2019; [Epub ahead of print].

47. Reckelhoff JF. Sex steroids, cardiovascular disease, and hypertension: unanswered questions and some speculations. Hypertension. 2005;45(2): 170-4.

48. Tsuji T, Ohishi K, Takeda A, Goto D, Sato T, Ohashi N, Fujigaki Y, Kato A, Yasuda $\mathrm{H}$. The impact of serum uric acid reduction on renal function and blood pressure in chronic kidney disease patients with hyperuricemia. Clin Exp Nephrol. 2018;22(6):1300-8.

\section{Publisher's Note}

Springer Nature remains neutral with regard to jurisdictional claims in published maps and institutional affiliations.

Ready to submit your research? Choose BMC and benefit from:
- fast, convenient online submission
- thorough peer review by experienced researchers in your field
- rapid publication on acceptance
- support for research data, including large and complex data types
- gold Open Access which fosters wider collaboration and increased citations
- maximum visibility for your research: over 100M website views per year
At BMC, research is always in progress.
Learn more biomedcentral.com/submissions

